International Journal of Biology, Pharmacy and Allied Sciences (IJBPAS)

'A Bridge Betueen Caboratory med QRando'

\author{
www.ibpas.com
}

\title{
AN OVERVIEW OF CARBON NANOMATERIALS FOR WASTEWATER TREATMENT
}

\section{PURNIMA NIMSE ${ }^{1}$, PRIYA MISHRA ${ }^{2}$, SHRUTIKA JAYBHAYE ${ }^{3}$, R.S. LOKHANDE ${ }^{1}$ AND SANDESH JAYBHAYE, ${ }^{2, *}$}

1: Department of Chemistry, Jaipur National University, Jaipur, India

2: Department of Chemistry, B.K. Birla College, Kalyan, India

3: Department of Architecture and Planning, Vivekanand Global University, Jaipur, India

*Corresponding Author: Sandesh Jaybhaye; E Mail: jaysandesh@gmail.com

Received $19^{\text {th }}$ July 2021; Revised $20^{\text {th }}$ Aug. 2021; Accepted 29 ${ }^{\text {th }}$ Sept. 2021; Available online $1^{\text {st }}$ Nov. 2021

https://doi.org/10.31032/IJBPAS/2021/10.11.1031

\begin{abstract}
Contaminated wastewater can cause a major problem to environment. Because of
\end{abstract} some regulatory requirement and industries towards sustainability some leading companies in the chemical industries working in the removal of non-toxic and toxic chemicals to purify water. Research in Nanotechnology has a immediate effect in early decades and offered many approaches for waste water treatment. By using carbon-based nanomaterials, pollutants could be removed more effectively from contaminated water as compared to common charcoal filters and common effluent water treatment plant. These types of nanomaterials show better results in effluent water treatment as compared with other materials. Moreover, the carbon-based nanomaterials have play vital role in waste water treatment and a powerful tool to get rid of different organic pollutants from water.

This Study involves analysis of hazardous substances that discharged into the environment through wastewater during the manufacturing processes of chemical industries and their treatment by using carbon nano materials. The synthesis of carbon nanotubes was carried from the decomposition of Acetylene gas in presence of inert atmosphere of Nitrogen at $850 \mathrm{oC}$ 
over Iron catalyst. Details of the analysis can be presented through the comparison of different parameters such as BOD, COD, DO parameters of effluent before and after carbon nano tubes treated. These results may offer new opportunities to expanding nano applications in industry and technology.

\section{Keywords: Acetylene, Biological Oxygen Demand, Carbon Nanotubes, Catalyst, Wastewater}

\section{INTRODUCTION}

Wastewater is a resource that is too valuable to sustainability, especially in an increasingly water-scarce world. Wastewater from large cities is often discharged directly into rivers or seas without treatment, leading to pollution and posing a threat to the health of ecosystems and people. But under the right conditions, wastewater can be recycled for agriculture, landscapes or industry, all of which tend to use huge quantities of the stuff [1]. Nanotechnology is an area of research that has progressive at such a speed in early decades and offered many opportunities for water treatment research. In modern era, nanomaterials have been considered that can convert the energy from several resources into empowering them to achieve special goals through various mechanisms [2].

\section{Carbon nanomaterial}

have emerged as promising catalysts for wate r purification. Chemical vapor deposition (CVD) technique was first reported to produce Multi walled carbon Nanotubes (MWNTs) by Endo and his research group. Three years later, Dai in Smalley's group successfully adapted CO-based CVD to produce single walled carbon nanotubes (SWNTs). CVD technique can be achieved by taking a carbon source in the gas phase and using an energy source, to transfer energy to a gaseous carbon molecule. The CVD process uses hydrocarbons as the carbon sources including methane, carbon monoxide and acetylene [3]. In addition to regulatory criteria, all companies shall assure compliance with the applicable national and local legal environmental requirements applicable to their processing/manufacturing stages (including those referring to emissions to air, wastewater discharge as well as disposal of waste and sludge). Wastewater from all wet processing units shall be treated in an internal or external functional wastewater treatment plant before discharged to environment. The present work can be helpful to the different brands, value chain retailers and associates committed to eliminating hazardous chemicals from the chemical industries. This research work helps to study carbon-based nanomaterial use in 
the context of industrial wastewater treatment and also recycling of Waste water discharge After treatment by using carbon-based nanomaterial [4]. Carbon nanotube (CNT) have great potential as absorbent materials for organic wastewater treatment owing to their high specific surface area, mesoporous structure, tuneable surface properties, and high chemical stability; these properties allow them to endure harsh wastewater conditions, such as acidic, basic, and salty conditions at high concentrations or at high temperatures.

$$
\text { In this work we analyzed }
$$
wastewater that discharged into the environment during the manufacturing processes of chemical industries and their treatment by using carbon nano materials. We compared different parameters such as Biological oxygen demand (BOD), Chemical Oxygen Demand (COD) of effluent before and after carbon nano tubes treated. These results may open new doors to expanding nano applications in industry and technology.

\section{MATERIALS AND METHODS \\ Preparation of Catalyst}

Mixture of Iron (III) nitrate powder and urea were prepared using urea as a combustion fuel, with ration of $1: 3$. The mixture was heated to $75^{\circ} \mathrm{C}$, added dropwise water under constant stirring at $500 \mathrm{rpm}$, and further stirred for $30 \mathrm{~min}$. All synthesized iron oxide nanoparticles were washed thrice with distilled water at $75^{\circ} \mathrm{C}$ and dried in an oven at $90^{\circ} \mathrm{C}$. The dried precursors of iron oxide nanoparticles were heated for $2 \mathrm{~h}$ at $600^{\circ} \mathrm{C}$ and form Iron catalyst [5-6].

\section{Synthesis of Carbon Nano Fibres}

The synthesis of CNFs was carried out using acetylene by CVD method using horizontal furnace. In this experiment The CNFs was prepared from acetylene by CVD process. The pyrolyzing apparatus presented in Figure 1. In this method one-meter-long quartz tube kept inside the furnace has been used. Iron particle was kept in quartz boat and placed inside the tube furnace. Nitrogen gas was passed in to the furnace tube at the flow rate of $0.4 \mathrm{cc} / \mathrm{min}$ to create inert atmosphere. After $5 \mathrm{~min}$. of passing gas the pyrolysis was tried at $850^{\circ} \mathrm{C}$. As soon as the temperature reached, the acetylene gas was allowed to pass very slowly at a flow rate of $0.4 \mathrm{cc} / \mathrm{min}$. for $2 \mathrm{~h}$. and heating was continued for $3 \mathrm{~h}$ [7-9]. At constant set temperature in an inert atmosphere of nitrogen. The furnace was allowed to cool down to room temperature, and then the pyrolyzed material was collected from the furnace. 




Figure 1: Synthesis of CNFs using Horizontal Linton's CVD furnace

\section{Purification of CNFs-}

Impurities like metal particles and amorphous carbon were removed by soaking of CNFs into acids $(50 \% \mathrm{HCL}$ and Nitric Acid solution separately) for $12 \mathrm{~h}$. Nitric acid had an effect specifically on metal catalyst [10].

\section{Characterization}

Morphology of Carbon nano fiber was analyzed by using X-ray diffraction analysis (XRD) to determine crystallographic structure of CNFs and scanning electron microscope (SEM)

\section{Waste water treatment}

Filtration of water is final process for this research work. We have given 3 layers in burette to filter the sample. We have used cotton plug in burette then kept CNFs and again cover it with cotton plug and then filtered the sample with Flow rate of $50 \mathrm{ml} / \mathrm{min}$.

\section{Analysis of Waste water}

Waste water collected from the Ulhas river treated with CNFs and filtrate was analyzed by using $\mathrm{pH}$, Conductivity, BOD and COD.

\section{RESULTS AND DISCUSSION}

Nano sized Iron Catalyst was prepared by urea decomposition method. During preparation of catalyst 1:3 proportion of ferric nitrate and urea gave the uniform shape and size catalyst. CVD method is economical method for production of qualitative and quantitative CNFs using acetylene in presence of nitrogen gas at $850^{\circ} \mathrm{C}$ over Iron catalyst. The photograph of as grown CNFs deposited on Iron catalyst in a quartz boat is shown Figure 2 .

The diameter $5 \mathrm{f}$ purified CNFs obtained using acetylene over Iron catalyst is found to be $50 \mathrm{~nm}$. SEM image of CNFs obtained using acetylene is shown in Figure 3.

Analysis of waste water- After implementing sampling analysis plan, Industrial effluent 
collected from Ulhas river near Shahad. Experimental Observations before and after treatment are mentioned in Table 1.
A glass soxhlet apparatus was used and the operating parameters investigated included flow rate, recycle ratio, saturation pressure and quantity of CNFs used.

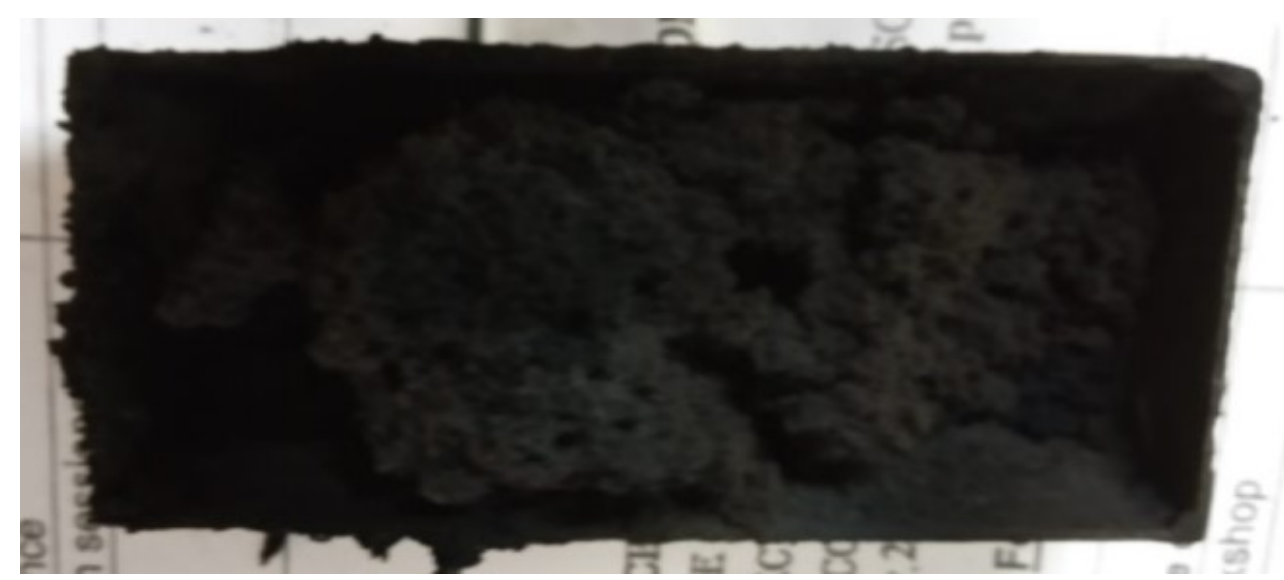

Figure 2: Photograph of as grown CNFs using acetylene by CVD process

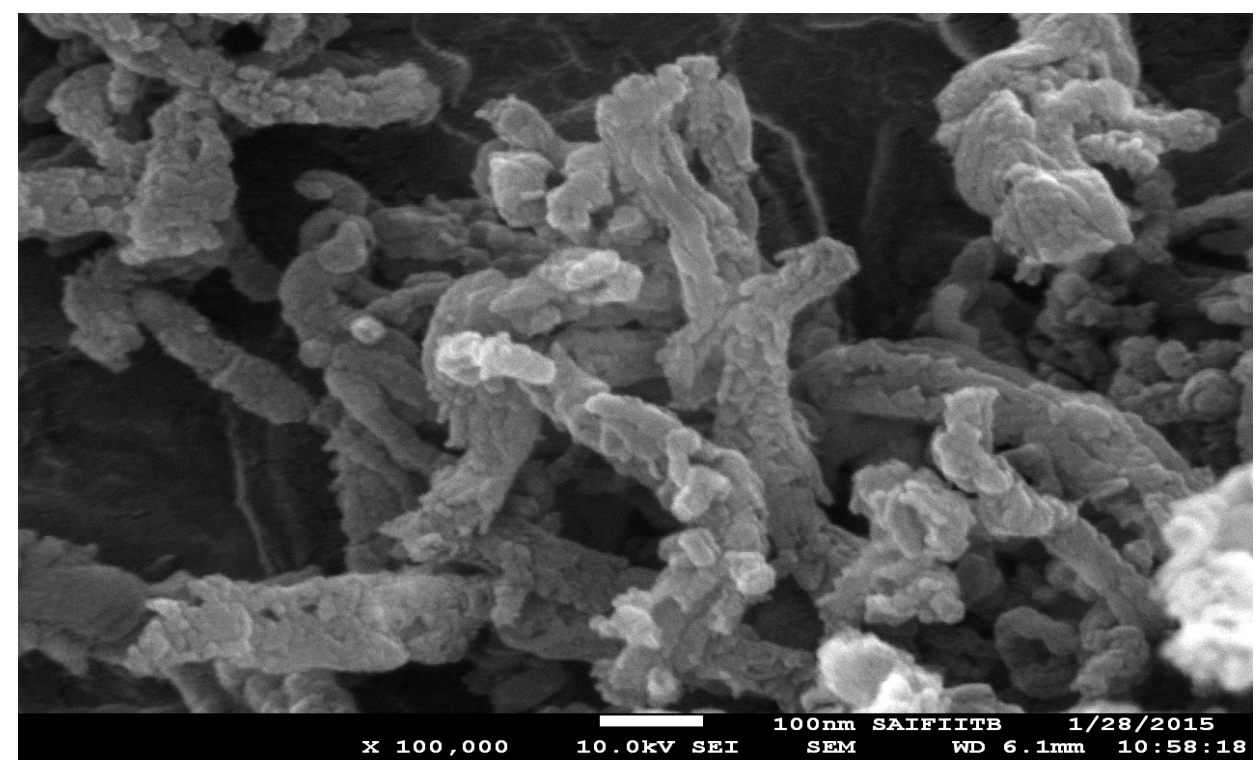

Figure 3: SEM Image of purified CNFs obtained

Table 1: Experimental Observations of Before and after treatment

\begin{tabular}{|c|c|c|}
\hline \multirow{2}{*}{ Parameters } & \multicolumn{2}{|c|}{ Observations } \\
\cline { 2 - 3 } & Before Treatment & After Treatment \\
\hline pH & 5.6 & $\mathbf{7 . 2}$ \\
\hline Conductivity & $\mathbf{0 . 1 8 0} \mathrm{ms} / \mathrm{cm}$ & $\mathbf{0 . 1 4 5} \mathbf{~ m s} / \mathbf{c m}$ \\
\hline BOD & 256 & 110 \\
\hline COD & 340 & 104 \\
\hline
\end{tabular}




\section{CONCLUSION}

Nanosized Iron catalyst successfully prepared by using urea decomposition method. This catalyst was used to synthesis of CNFs by decomposition of acetylene as carbon source. The as grown CNFs were used to treat industrial waste water. Considering parameters of $\mathrm{BOD}, \mathrm{COD}$ concluding experiment trials which meets the regulatory requirement. Observations of different parameters like BOD, COD of waste water noted before and after treatment. In this experiment we have observed applicable parameter of local and national legal requirement. All experimental parameters observed within range of legal requirements. It was found that for dosages of purified CNFs in the range of $50-150$ $\mathrm{mg} / \mathrm{l}$, the removal efficiencies for BOD increased from $25-80 \%$.

\section{Acknowledgement-}

Authors are grateful to Management of Jaipur National University, Rajasthan and B. K. Birla College Kalyan for their motivation and support for experimental work.

\section{REFERENCES}

[1] Un environment programme, news and stories, wastewater challenges and opportunities, 21-Mar-2017.

[2] Asim Ali Yaqoob, Tabassum Parveen, Khalid Umar, and Mohamad
Nasir Mohamad Ibrahim, Role of Nanomaterials in the Treatment of Wastewater: A Review, Journal Water, 2020, Volume12(Issue 2), 495

[3] H. Dai, A.G. Rinzler, P. Nikolaev, A. Thess, D.T. Colbert, R.E. Smalley, Single-wall nanotubes produced by metal-catalyzed disproportionation of carbon monoxide, Chem. Phys. Lett., 1996, 260, 471-475

[4] ZDHC(Zero Discharge of Hazardous Chemicals) waste water guideline, Version 1.1, 2019

[5] Diana Kostyukova, Yong Hee Chung, Synthesis of Iron Oxide Nanoparticles Using Isobutanol, Journal of Nanomaterials, vol. 2016, Article ID 4982675, 9 pages, 2016.

[6] Bahaa Abu-Zied, Abdullah M. Asiri, Urea-Based Combustion Process for the Synthesis of Nanocrystalline Ni-La-Fe-O Catalysts, Journal of Nanomaterials, vol. 2012, Article

ID 428643, 7 pages, 2012.

[7] Gaud B, Singh A, Jaybhaye S, Narayan H. Synthesis of Carbon Nano Fiber from Organic Waste and Activation of its Surface Area. Int J Phys Res Appl. 2019; 2: 056-059 
[8] Sandesh Jaybhaye, Pandurang Satpute and Mandar Medhi, Carboxylation of Multi-walled Carbon Nanotubes by Ultra sonication, Int. Journal of Chemistry, Vol. 3 (2) (2014) pp 224 228.

[9] Jaybhaye Sandesh, Sharon Madhuri, Sharon Maheshwar, Sathiyamoorthy D. and Dasgupta K. Semi conducting Carbon Nanofibers and Hydrogen Storage, Int. Journal, Synthesis and Reactivity in Inorganic, Metal-
Organic, and Nano-Metal Chemistry (SRINMC), 37(6), (2007) 473 - 476.

[10] Vilas Khairnar, Maheshwar Sharon, Sandesh Jaybhaye, Michael Neumann, Development of Super capacitor Using Carbon Nanofibers Synthesized from Ethanol, Int. Journal, SRINMC Vol. 36(2), (2006)171-173. 